\title{
DO MUNDO PARA A LINGUAGEM: A VERDADE NO ATOMISMO LÓGICO DE RUSSELL
}

\author{
From the world to the language: the truth in the logical atomism by Russell
}

\author{
César Fernando Meurer*
}

\begin{abstract}
Resumo: Russell pensava que a estrutura última da realidade se revelaria na análise lógica de sentenças verdadeiras uma vez que estas espelham os fatos que expressam. Denominada 'atomismo lógico' essa posição ganhou adeptos e, em pouco tempo, status de paradigma filosófico alternativo ao idealismo e ao pragmatismo. No presente artigo, abordo o atomismo como uma doutrina metafísica e apresento, com algum pormenor, a concepção de verdade dessa doutrina. Tomo como referência principal as conferências que Russell ditou em 1918, cujo texto chega a nós sob o título The Philosophy of Logical Atomism. A exposição é feita em três seções: na primeira apresento o que o autor entende por 'fato'. $\mathrm{Na}$ segunda discuto o seu entendimento de 'crença'. Na terceira, com base nas anteriores, foco o cerne da teoria da verdade do atomismo lógico: a relação 'crença \& fato'. O atomismo lógico comporta uma concepção correspondentista de verdade. Compreendê-la implica compreender a imbricação da metafísica com a epistemologia por meio da lógica. Em alusão ao título, podese dizer que o percurso do mundo para a linguagem é logicamente pavimentado.
\end{abstract}

Palavras-chave: Verdade. Atomismo Lógico. Teoria Correspondentista. Fatos. Russell.

\begin{abstract}
Russell thought that the ultimate structure of the reality would reveal itself in the logical analysis of true sentences, once that they reflect in the facts that they express. Named as 'logical atomism', this position gained supporters and, in a little while, status of alternative philosophical paradigm to the idealism and to the pragmatism. In the present article I approach the atomism as a metaphysical doctrine and I present, with some particularity, the conception of truth of this doctrine. I take as main reference the talks that Russell dictated in 1918, whose text comes to us under the title The Philosophy of Logical Atomism. The exposition is made in three sections: in the first I present what the author understands as 'fact'. In the second I discuss his understanding of 'belief'. In the third, with basis in the previous ones, I focus the core of the theory of the truth of the logical atomism: the relation 'belief \& fact'. The logical atomism holds a corresponding conception of truth. Understanding it implies to understand the imbrications of the metaphysics with the epistemology by means of the logic. In allusion to the title, one may say that the trajectory of the world to the language is logically paved.
\end{abstract}

Keywords: Truth. Logical Atomism. Correspondence Theory. Facts. Russell.

* Doutorando pelo Programa de Pós-Graduação em Filosofia da Universidade do Vale do Rio dos Sinos (UNISINOS). Contato: cfmeurer@yahoo.com.br

\begin{tabular}{|c|c|c|c|c|c|}
\hline intuitio & $\begin{array}{c}\text { ISSN } \\
1983-4012\end{array}$ & Porto Alegre & Vol.7 - No.1 & $\begin{array}{c}\text { Junho } \\
2014\end{array}$ & p.182-191 \\
\hline
\end{tabular}


Conforme Haack ${ }^{1}$, o criador da doutrina denominada 'atomismo lógico' foi Wittgenstein, mas a versão de Russell apareceu primeiro em um conjunto de conferências pronunciadas em Londres, nos primeiros meses de 1918, e posteriormente publicado sob o título The Philosophy of Logical Atomism $^{2}$. Efetivamente Russell anota, no início desse texto, que está tratando de explicar ideias que aprendeu com Wittgenstein.

O presente artigo visa uma compreensão algo detalhada da concepção de verdade do atomismo lógico de Russell. Seguirei os argumentos apresentados nas conferências de 1918. Conforme Ayer ${ }^{3}$, Russell manteve-se fiel à concepção atomista até o final da vida. Ele mesmo confirma-o em Meu Pensamento Filosófico, dado à estampa em 1959.

Durante todo o meu desenvolvimento filosófico, desde que abandonei o monismo, conservei, apesar de mudanças, certas crenças fundamentais, que não sei de que maneira demonstrar, mas das quais não consigo duvidar. A primeira delas, que me parece tão óbvia que me envergonharia referir-me a ela, não fora a circunstância de deparar com opinião contrária, é que a verdade depende de alguma espécie de relação com o fato. A segunda é que o mundo consiste de muitas coisas relacionadas entre si. A terceira é que a sintaxe - isto é, a estrutura das sentenças deve ter alguma relação com a estrutura dos fatos, pelo menos naqueles aspectos da sintaxe que são inevitáveis e não peculiares a esta ou àquela língua. Finalmente, existe um princípio a respeito do qual me sinto menos seguro, mas ao qual desejo manter-me fiel [...] Refiro-me ao princípio de que aquilo que se pode dizer acerca de um complexo pode ser dito sem que nos refiramos a ele, expondo suas partes e suas relações mútuas. ${ }^{4}$

Essa passagem providencia um contexto: as quatro crenças fundamentais constituem, por assim dizer, o "núcleo duro" da filosofia de Russell. Questões metafísicas, lógicas e epistemológicas estão aí profundamente interconectadas. Por onde começar? Nas conferências de 1918 o autor insistiu que o percurso adequado é do mundo para a linguagem. Por conta dessa recomendação é acertado tomar o atomismo como uma doutrina metafísica que comporta uma teoria correspondentista da verdade. Veremos que a ideia de correspondência explicita o modo como Russell vincula a metafísica à epistemologia por meio da lógica. Por conseguinte, o propósito de elucidar a concepção de verdade é, em boa medida, análogo ao trabalho iluminar esse vínculo.

Nas conferências de 1918, Russell apresentou a tese central do atomismo nos seguintes termos: "O mundo pode ser analisado num certo número de coisas separadas com relações e assim por diante" . Note o leitor que essa tese está em sintonia com a segunda das crenças fundamentais que ele enumerou em 1959, de que o mundo consiste de muitas coisas e que essas muitas coisas se relacionam

${ }^{1}$ HAACK, S.. Filosofia das lógicas. Tradução de Cezar Augusto Mortari e Luiz Henrique de Araújo Dutra. São Paulo: Editora Unesp, 2002, p.133.

${ }^{2}$ Uma parte do texto apareceu no The Monist, 28 (outubro de 1918) e o restante no The Monist, 29 (julho de 1919). A matéria foi reeditada em 1956, na coletânea Logic and knowledge. Utilizo a seguinte edição: RUSSELL, Bertrand. The Philosophy of logical atomism. London: Routledge Classics, 2010.

${ }^{3}$ AYER, Alfred. As ideias de Bertrand Russell. Tradução de Leonidas Hegenberg e Octanny Silveira da Mota. São Paulo: Cultrix; Editora da Universidade de São Paulo, 1974, p.102.

${ }^{4}$ RUSSELL, Bertrand. Meu pensamento filosófico. Tradução de Brenno Silveira. São Paulo: Companhia Editora Nacional, 1960, p.136-137 - itálicos meus.

${ }^{5}$ RUSSELL, Bertrand. The Philosophy of logical atomism, p.15.

\begin{tabular}{|c|c|l|l|l|l|}
\hline intuitio & $\begin{array}{c}\text { ISSN } \\
1983-4012\end{array}$ & Porto Alegre & Vol.7- $\mathrm{N}^{\mathrm{o}} .1$ & $\begin{array}{c}\text { Junho } \\
2014\end{array}$ & p.182-191 \\
\hline
\end{tabular}


umas com as outras. Ao que me consta, as coisas separadas são particulares simples com qualidades e relações. Duas ideias, poderíamos chamá-las de premissas, fornecem sustentação à tese: "o mundo contém fatos, que são o que são, não importando o que decidimos pensar acerca deles", e "existem também crenças, que se referem aos fatos e que por referência aos fatos são ou verdadeiras ou falsas"6. Outra vez a sintonia com os pilares fundamentais apresentados, em 1959, faz-se notar.

Essa esquematização em forma de argumento (premissas e conclusão) servirá de fio condutor para o que segue. Iniciarei a exposição com o que Russell entende por 'fato'. Depois, na segunda seção, abordarei o seu entendimento de 'crença' e, finalmente, na terceira parte, a relação 'crença \& fato'. Essa relação é o cerne da teoria da verdade do atomismo lógico russelliano e, conforme sugeri há pouco, uma amostra do quão imbricadas aí estão a metafísica, a epistemologia e a lógica.

\section{A concepção de fato}

O mundo pode ser analisado. Podemos descrever o que existe. Tal descrição, caso se decida fazê-la, não estará completa com a enumeração das coisas particulares. A descrição completa do mundo objetivo inclui, segundo Russell, as relações e as propriedades das coisas. E quando a atenção se volta para propriedades e relações, estamos percebendo o que o autor chama 'fatos'.

Fatos pertencem ao mundo objetivo tanto quanto as coisas particulares, ainda que não se confundam com elas. "Expressamos um fato quando dizemos que certa coisa tem determinada propriedade ou que tem certa relação com outra coisa; mas a coisa que tem a propriedade ou a relação não é o que chamo um 'fato"'?

Russell está ciente das dificuldades de oferecer uma definição precisa de 'fato'. Em algumas passagens, quando a circunstância requer uma elucidação do termo, lê-se que fato é "a espécie de coisa que torna verdadeira ou falsa uma proposição";; "a espécie de coisa que se expressa por uma sentença inteira, não por um nome simples"9; "a espécie de coisa que é o caso quando o nosso enunciado é verdadeiro e que não é o caso quando o nosso enunciado é falso" ${ }^{10}$. Essas definições são apenas aproximadas, pois deixam "fato" como "espécie de coisa" e remetem a questão para as proposições ou sentenças.

Mais esclarecedora é a passagem onde o autor diz que um fato, seja ele qual for, é uma "complexidade objetiva genuína"11. Sendo o fato complexo, sua apreensão também será complexa. A complexidade objetiva dos fatos, ainda que não seja definível, é apreensível e descritível. Eis porque Russell pensa que "o procedimento apropriado e ordenado começa da complexidade do mundo e

\footnotetext{
${ }^{6}$ RUSSELL, Bertrand. The Philosophy of logical atomism, p.06.

${ }^{7}$ RUSSELL, Bertrand. The Philosophy of logical atomism, p.07.

${ }^{8}$ RUSSELL, Bertrand. The Philosophy of logical atomism, p.06.

${ }^{9}$ RUSSELL, Bertrand. The Philosophy of logical atomism, p.07.

${ }^{10}$ RUSSELL, Bertrand. The Philosophy of logical atomism, p.18.

${ }^{11}$ RUSSELL, Bertrand. The Philosophy of logical atomism, p.24.
}

\begin{tabular}{|c|c|l|l|l|l|}
\hline intuitio & $\begin{array}{c}\text { ISSN } \\
1983-4012\end{array}$ & Porto Alegre & Vol.7- $\mathrm{N}^{\mathrm{o}} .1$ & $\begin{array}{c}\text { Junho } \\
2014\end{array}$ & p.182-191 \\
\hline
\end{tabular}


chega à complexidade da proposição"12. Por isso, tem razão Kirkham ${ }^{13}$ ao classificar a teoria da verdade de Russell como um projeto metafísico ${ }^{14}$.

O percurso do mundo para a linguagem aposta na possibilidade de apreender a complexidade genuína dos fatos e desmembrá-la "em suas partes componentes, das quais pode-se alterar um componente sem alterar os outros, e um componente pode ocorrer em alguns fatos, embora não ocorra em todos" ${ }^{\prime 15}$. Segue, do êxito desse procedimento, que a unidade última da análise do mundo são os assim chamados 'átomos lógicos'. Em outras palavras: todas as coisas que nós experienciamos podem ser analisadas em átomos lógicos. Se assim for, então a lógica atomista que Russell defende supera a lógica monista. Quer dizer: a multiplicidade do mundo não é apenas aparente, como se poderia pensar sob a influência de alguém "que mais ou menos segue Hegel"16. Para ilustrar esse ponto, Santos ${ }^{17}$ sugere um paralelo com as teorias científicas: o que vale para essas teorias, de serem formuladas em termos de expressões simples para objetos, propriedades e relações, valeria também para a metafísica. Tivéssemos uma linguagem logicamente perfeita, diz Russell, poderíamos reduzir o mundo a objetos, propriedades e relações simples e teríamos "num relance a estrutura lógica dos fatos"

O mundo possui certa estrutura lógica apreensível e a linguagem pode espelhá-la. Daí que o caminho do mundo para a linguagem é logicamente pavimentado; a estrutura última da realidade se revela na análise lógica de sentenças que expressam fatos.

Russell chama a atenção para a forma lógica dos fatos ao mostrar que eles podem ser classificados segundo uma hierarquia. No nível mais simples está aquele tipo de fato que consiste "na posse de uma qualidade por parte de uma coisa particular". No nível seguinte estão os fatos nos quais temos uma relação diádica, do tipo "isto está à esquerda daquilo". "A seguir chegamos àqueles [fatos] em que temos uma relação triádica entre três particulares" ${ }^{\prime 19}$. Essa hierarquia pode ser levada adiante, como se queira.

Os fatos também podem ser classificados segundo sua espécie. Sob esse prisma entra em consideração, por um lado, a distinção de fatos particulares e gerais, e, por outro, a de fatos positivos e negativos. O autor anota que essas distinções são de grande importância e acrescenta que é possível

12 RUSSELL, Bertrand. The Philosophy of logical atomism, p.24.

13 KIRKHAM, R. Teorias da verdade: uma introdução crítica. Tradução de Alessandro Zir. São Leopoldo: Editora Unisinos, 2003, p.65.

${ }^{14}$ Kirkham constrói um quadro abrangente no qual as teorias da verdade são agrupadas em projeto metafísico, projeto da justificação e projeto dos atos de fala. São metafísicas aquelas teorias que visam "identificar em que consiste a verdade; o que significa para uma afirmação ser verdadeira” (KIRKHAM, 2003, p. 39).

${ }^{15}$ RUSSELL, Bertrand. The Philosophy of logical atomism, p.19.

${ }^{16}$ RUSSELL, Bertrand. The Philosophy of logical atomism, p.02.

17 SANTOS, Luis Henrique dos. "Vida e obra". In: RUSSELL, Bertrand. Ensaios escolhidos. Tradução de Pablo Rubén Mariconda. São Paulo: Abril Cultural, 1978, p.xix.

${ }^{18}$ RUSSELL, Bertrand. The Philosophy of logical atomism, p.25.

${ }^{19}$ RUSSELL, Bertrand. The Philosophy of logical atomism, p.26.

\begin{tabular}{|c|c|l|l|l|l|}
\hline intuitio & $\begin{array}{c}\text { ISSN } \\
1983-4012\end{array}$ & Porto Alegre & Vol.7- $\mathrm{N}^{\mathrm{o}} .1$ & $\begin{array}{c}\text { Junho } \\
2014\end{array}$ & p.182-191 \\
\hline
\end{tabular}


produzir outras. Conforme essa linha de pensamento, fazer filosofia consiste, em boa medida, em inventariar fatos. Como disse Pears ${ }^{20}$, isso soa como se fosse física, mas é metafísica.

O que esse inventário não pode perder de vista é que todos os fatos pertencem ao mundo objetivo e, não importa a sua forma lógica, "deve[m] ser composto[s] inteiramente de constituintes que existam, e não de constituintes que não existam"21. No entendimento de Russell, a teoria das descrições é o recurso apropriado para evitar compromisso ontológico com entidades inexistentes.

Na tônica de um balanço abrangente dos fatos Russell menciona também fatos atômicos e fatos existenciais. O critério geral de classificação é a forma lógica, que pode ser apreendida e exposta em suas partes componentes. Esse exame aponta que a verdade consiste em correspondência da forma da proposição ou sentença [que se adequa] com a forma do fato.

Os fatos em nada dependem do pensamento ou da linguagem. Não são, eles mesmos, verdadeiros ou falsos. Tais atributos, $\mathrm{V}$ e F, são algo que cabe a outras entidades complexas: as proposições. É verdadeira a proposição que espelha um fato. Para tornar isso mais claro é necessário estudar o que o autor entende por crença. Esse é o tema do próximo tópico.

\section{A concepção de crença}

O ponto de partida para delinear o que Russell entende por 'crença', já mencionado na introdução, é a afirmação: "existem também crenças, que se referem aos fatos e que por referência aos fatos são ou verdadeiras ou falsas" ${ }^{2}$. Grifo essa passagem pela sua posição na obra em exame e pela sonoridade ligeiramente dissonante do termo 'crenças' que aí observo. A primeira vista teria sido mais apropriado dizer que existem também proposições ou sentenças que se referem aos fatos.

Para Russell, 'crença' é algo que se expressa através de uma sentença. É o que se lê no The Problems of Philosophy, que apareceu em 1912. Sem usar o termo 'atomismo', essa obra oferece uma explicação marcadamente psicológica da correspondência de sentenças verdadeiras com fatos. Nessa explicação, acreditar e ajuizar designam o mesmo ato mental de entrelaçar, num complexo, determinados termos ${ }^{23}$.

O termo 'crença' permite falar também da crítica que Russell dirige à concepção pragmatista de crença. A seu ver, concepção de crença do atomismo lógico é inconciliável com a concepção pragmatista de crença. A seguinte passagem, de O meu Pensamento Filosófico, situa essa divergência:

O ponto essencial em que difiro do pragmatismo é este: o pragmatismo afirma que uma crença há de ser julgada verdadeira se possui certas espécies de efeitos,

\footnotetext{
${ }^{20}$ PEARS, David. Introduction to the 1985 edition. In: RUSSELL, Bertrand. The Philosophy of logical atomism. London: Routledge Classics, 2010, p.07.

${ }^{21}$ RUSSELL, Bertrand. The Philosophy of logical atomism, p.52.

${ }^{22}$ RUSSELL, Bertrand. The Philosophy of logical atomism, p.06.

${ }^{23}$ Cf. RUSSELL, Bertrand. Os problemas da filosofia. Tradução de Desidério Murcho. Lisboa: Edições 70, 2008; Kirkham analisa o correspondentismo de Russell a partir dessa obra (Cf. KIRKHAM, R. Teorias da verdade: uma introdução crítica).
}

\begin{tabular}{|c|c|l|l|l|l|}
\hline intuitio & $\begin{array}{c}\text { ISSN } \\
1983-4012\end{array}$ & Porto Alegre & Vol.7- $\mathrm{N}^{\mathrm{o}} .1$ & $\begin{array}{l}\text { Junho } \\
2014\end{array}$ & p.182-191 \\
\hline
\end{tabular}


enquanto que eu afirmo que uma crença empírica deve ser considerada verdadeira se possui certas espécies de causas. ${ }^{24}$

Conjecturo que Russell usou o termo 'crença' com o intuito de demarcar sua posição em relação ao pragmatismo. É importante frisar que se trata, nas conferências de 1918, de uma ocorrência isolada, em nenhum momento a afirmação de que há "crenças que se referem aos fatos" é, nesses mesmos termos, reapresentada. Nos parágrafos mais avançados, o assunto é retomado com a palavra 'proposição' e, eventualmente, 'sentença' ou 'enunciado' ${ }^{25}$. Passo, então, a essa terminologia.

Adiantei, no final da seção anterior, que as proposições espelham fatos e nisso reside sua possibilidade de verdade. Isso requer esclarecimentos. A primeira coisa a mencionar é que para Russell "uma sentença (ou proposição) é um símbolo apropriado para um fato"26. A noção de símbolo que o autor emprega é idêntica a do entendimento comum: símbolo é algo que significa alguma outra coisa. No caso da proposição, ela

é um símbolo complexo no sentido de que tem partes que também são símbolos: um símbolo pode ser definido como complexo quando tem partes que são símbolos. Numa sentença contendo várias palavras, as várias palavras são cada uma um símbolo, e a sentença que as compõe é portanto um símbolo complexo naquele sentido". ${ }^{27}$

Se a proposição é um símbolo complexo, então ela corresponde ao mundo não apenas nesse nível complexo, onde a contrapartida é o fato, mas também no nível das palavras para com as suas referências. Eis o exemplo do autor: "a palavra 'Sócrates' significa certo homem; a palavra 'mortal' significa certa qualidade; e a sentença 'Sócrates é mortal' significa certo fato" 28 .

Russell frisa que "as proposições não são nomes para os fatos"29. Nomear é essencialmente diferente de afirmar ou negar. As coisas simples são justamente os objetos suscetíveis de denotação por nomes próprios. Esse critério é oriundo da teoria das descrições, conhecida desde o On denoting (1905). A teoria das descrições, que não detalharei aqui, mostra que a expressão denotativa que não é um nome genuíno pode ser redescrita como um predicado. Justamente por causa da sua capacidade

\footnotetext{
${ }^{24}$ RUSSELL, Bertrand. Meu pensamento filosófico, p.154-155.

${ }^{25}$ Em certas discussões filosóficas se distingue 'proposição' de 'sentença', de 'enunciado', de 'frase', de 'juízo'. No texto em exame, Russell usa, sobretudo, 'proposição' e 'sentença'. Em algumas passagens, o leitor é levado a crer que ele os toma como sinônimos. Interpreto que Russell não toma 'proposição' como um objeto abstrato.

${ }^{26}$ RUSSELL, Bertrand. The Philosophy of logical atomism, p.12.

${ }^{27}$ RUSSELL, Bertrand. The Philosophy of logical atomism, p.10.

${ }^{28}$ RUSSELL, Bertrand. The Philosophy of logical atomism, p.12. Note o leitor que Russell lança mão do termo 'significa'. Dependendo das nossas preferências teóricas, essa palavra impulsiona distintas considerações. Penso que a teoria correspondentista da verdade é, nesse sentido, também uma teoria do significado. Acerca desse ponto é interessante uma passagem de Meu Pensamento Filosófico: "Foi em 1918 [...] que primeiro me interessei pela definição de 'significado' e pela relação entre a linguagem e os fatos. Até então eu encarara a linguagem como algo 'transparente' não tendo jamais examinado o que constitui a sua relação com o mundo nãolinguístico" (RUSSELL, Bertrand. Meu pensamento filosófico, p.124). Tanto quanto sei, o primeiro texto de Russell dedicado ao significado é o capítulo 10 de Análise da Mente (Cf. RUSSELL, Bertrand. A análise da mente. Tradução de Antônio Cirurgião. Rio de Janeiro: Zahar Editores, 1976).

${ }^{29}$ RUSSELL, Bertrand. The Philosophy of logical atomism, p.13.
}

\begin{tabular}{|c|c|l|l|l|l|}
\hline intuitio & $\begin{array}{c}\text { ISSN } \\
1983-4012\end{array}$ & Porto Alegre & Vol.7- $\mathrm{N}^{\mathrm{o}} .1$ & $\begin{array}{c}\text { Junho } \\
2014\end{array}$ & p.182-191 \\
\hline
\end{tabular}


para resolver enigmas sobre existência e identidade, essa teoria vigorou como paradigma filosófico por um longo período ${ }^{30}$.

Nomes próprios não têm a dualidade entre verdade e falsidade que é necessário manter para as proposições. Para assegurar a possibilidade de proposições falsas - detalhe de grande importância Russell argumenta que para cada fato há duas proposições, e não uma como poderíamos ser levados a imaginar. A articulação desse argumento é deveras perspicaz:

\footnotetext{
suponhamos que Sócrates está morto seja um fato. Temos duas proposições: 'Sócrates está morto' e 'Sócrates não está morto'. E para essas duas proposições que correspondem ao mesmo fato, existe um único fato no mundo que faz uma verdadeira e a outra falsa. ${ }^{31}$
}

Segue que não apenas as proposições verdadeiras têm relação com fatos, mas também as falsas. Quer dizer: a proposição ou tem a relação de "ser falsa para o fato" ou tem a relação "ser verdadeira para o fato" ${ }^{32}$. Isso posto, resta saber como se procede para averiguar se a relação é de um ou de outro tipo. Esse é o assunto da próxima seção. Com ele chegamos ao cerne do correspondentismo russelliano, onde a insistência "do mundo para a linguagem" se deixa compreender plenamente.

\section{A relação crença \& fato}

A teoria da verdade do atomismo lógico tem dois planos relacionados: o dos nomes próprios, símbolos para as coisas, e o das proposições, símbolos para os fatos. O exposto nos tópicos precedentes pode ser sumarizado nos seguintes termos:

As coisas no mundo possuem várias propriedades e acham-se em várias relações entre si. Que elas possuem essas propriedades e relações são fatos, e as coisas e suas

\footnotetext{
${ }^{30}$ Sobre o On Denoting, considero de grande proveito as análises de Pinto (Cf. PINTO, Paulo Roberto Margutti. "Análise argumentativa do texto On Denoting de B. Russell". Síntese Nova Fase, Belo Horizonte, v. 28, n. 90, p. 67-96, 2001) e Brito (Cf. BRITO, Adriano Naves de. Nomes próprios: semântica e ontologia. Brasília: Editora UNB, 2003, p.53-60). Dentre as inúmeras avaliações técnicas da teoria das descrições, gostaria de destacar Chateaubriand (Cf. CHATEAUBRIAND, O. Logical forms: truth and description. Campinas: CLE Unicamp, 2001, p.93-135) e Gamut (Cf. GAMUT, L. T. F. Lógica, lengua y significado: introducción a la lógica. 2.ed. Traducción de Cecilia Durán. Buenos Aires: Eudeba, 2009, p.161-167). Sobre a influência da teoria das descrições na filosofia posterior, considero apropriado mencionar o elogio de Wittgenstein (WITTGENSTEIN, Ludwig. Tractatus logico-philosophicus. Tradução e apresentação de José Arthur Giannotti. São Paulo: Companhia Editora Nacional e Editora da USP, 1968, p.71): “Toda filosofia é 'crítica da linguagem' [...] O mérito de Russell é ter mostrado que a forma aparentemente lógica da proposição não deve ser sua forma real". Tanto quanto sei, a teoria de Russell foi contraposta somente em 1950, por Strawson, no On Referring (Cf. STRAWSON, Peter. "Sobre referir". Tradução de Balthazar Barbosa Filho. In.: RYLE et.all. Ensaios. São Paulo: Abril Cultural, 1975). Russell respondeu às críticas Strawson. (Cf. RUSSELL, Bertrand. Meu pensamento filosófico, p.213-219).

${ }^{31}$ RUSSELL, Bertrand. The Philosophy of logical atomism, p.13.

${ }^{32}$ RUSSELL, Bertrand. The Philosophy of logical atomism, p.13.
}

\begin{tabular}{|c|c|l|l|l|l|}
\hline intuitio & $\begin{array}{c}\text { ISSN } \\
1983-4012\end{array}$ & Porto Alegre & Vol.7- $\mathrm{N}^{\mathrm{o}} .1$ & $\begin{array}{c}\text { Junho } \\
2014\end{array}$ & p.182-191 \\
\hline
\end{tabular}


qualidades ou relações são claramente, num ou noutro sentido, componentes dos fatos que possuem aquelas qualidades ou relações. ${ }^{33}$

As coisas, que designamos por nomes, participam de fatos, que afirmamos ou negamos com proposições. Se lembrarmos, uma vez mais, da recomendação de começar a análise pelos fatos e não pelas coisas, então a forma adequada de dizê-lo é a inversa: os fatos, que afirmamos ou negamos com proposições, são compostos de coisas simples que designamos por nomes, consideradas suas propriedades e relações.

Uma proposição, símbolo para um fato, expressa-se por palavras concatenadas. Para entendêla é preciso conhecer o vocabulário, a gramática e a sintaxe da linguagem. Mesmo uma proposição inédita pode ser compreendida quando esses requisitos estão atendidos.

Se a proposição é compreendida mediante o entendimento das palavras que a compõe, como se alcança o entendimento destas? Considere-se, por exemplo, que é um fato que cinco maçãs vermelhas estão no recipiente que está sobre a mesa. Russell orienta-nos a partir do fato, tomando-o como uma complexidade genuína. Para cada fato, como vimos, há duas proposições, sendo uma verdadeira e outra falsa. Nesse caso, a proposição verdadeira para o fato pode ser assim enunciada: 'Cinco maçãs vermelhas estão no recipiente que está sobre a mesa'. Qual seria a proposição falsa para esse mesmo fato? Porventura seria 'Cinco maçãs vermelhas não estão no recipiente que está sobre a mesa'? Poderia ser 'Cinco maçãs estão no recipiente que não está sobre a mesa'? A dificuldade se faz notar. Prossigamos com a problematização, agora voltando para as palavras componentes da sentença. Como se alcança o entendimento de 'cinco', de 'maçã', de 'vermelho' e assim por diante?

No que segue ensaiarei alguns movimentos de análise, seguindo o que Russell propõe. É um exercício. Concedo, de saída, que é um fato que cinco maçãs vermelhas estão no recipiente que está sobre a mesa.

$1^{\mathrm{a}}$ consideração: o fato é o que é, não importa o que pensamos acerca dele. Quer dizer: em sentido algum ele depende do pensamento. É uma ocorrência externa.

$2^{\mathrm{a}}$ consideração: o fato pode ser desmembrado em suas partes componentes. Uma maneira de fazê-lo seria separá-lo em dois: é um fato que cinco maçãs vermelhas estão no recipiente e é outro fato que o recipiente está sobre a mesa. Um ulterior desmembramento consiste em notar que é um fato que as cinco maçãs são vermelhas (e não duas verdes e três vermelhas, por exemplo).

$3^{\mathrm{a}}$ consideração: pode-se alterar um componente sem alterar os outros. É perfeitamente possível trocar as cinco maçãs vermelhas por cinco maçãs verdes, o que resultaria em outro fato: cinco maçãs verdes estão no recipiente que está sobre a mesa. Muitas outras alterações são possíveis (por exemplo: cinco maçãs vermelhas estão no recipiente que está embaixo da mesa; cinco maçãs vermelhas estão sobre a mesa e o recipiente está embaixo da mesa,...). Ficou claro, nessa consideração,

${ }^{33}$ RUSSELL, Bertrand. The Philosophy of logical atomism, p.18-19.

\begin{tabular}{|c|c|c|c|c|c|}
\hline intuitio & $\begin{array}{c}\text { ISSN } \\
1983-4012\end{array}$ & Porto Alegre & Vol.7 $-\mathrm{N}^{\mathrm{o}} .1$ & $\begin{array}{c}\text { Junho } \\
2014\end{array}$ & p.182-191 \\
\hline
\end{tabular}


que um componente pode ocorrer em muitos fatos. Sinal evidente da multiplicidade analisável do mundo.

$4^{\mathrm{a}}$ consideração: o símbolo apropriado para um fato é uma proposição, e é o fato que torna verdadeira ou falsa a proposição. Se é um fato que cinco maçãs vermelhas estão no recipiente, então a proposição verdadeira para esse fato é 'Cinco maçãs vermelhas estão no recipiente'. Uma proposição pode ser verdadeira ou falsa para um fato. $\mathrm{O}$ fato, por si mesmo, não tem a dualidade entre verdadeiro e falso.

$5^{\mathrm{a}}$ consideração: a proposição é um símbolo complexo, na natureza do qual nada informa se ele é verdadeiro ou falso. Houvesse no próprio símbolo uma marca da verdade ou da falsidade, se poderia ampliar o conhecimento do mundo examinando tão somente proposições, sem olhar para os fatos. Sem olhar para as maçãs, para o recipiente e para a mesa, não se pode saber qual sentença é verdadeira e qual é falsa. A verdade da sentença depende derradeiramente do fato.

$6^{a}$ consideração: a proposição é um símbolo complexo porque contém palavras que também são símbolos. É um símbolo aquela palavra que expressa alguma coisa particular. Chamamo-lo de nome ou nome próprio. Aqui uma questão importante se impõe ao curso da análise: como distinguir nomes próprios de outras palavras? Quais destas são nomes: 'cinco', 'maçã', 'vermelho', 'estar no' e 'recipiente'?

A questão deixa à vista que "as características lógico-formais das proposições são bastante diferentes das características dos nomes" ${ }^{\prime 34}$. A característica do nome, por assim dizer, é a relação única que ele tem com o que nomeia. Quer dizer: "um nome só pode nomear um particular ou, se não o nomeia, não é em absoluto um nome, é um ruído" ${ }^{35}$. O nome tem um modo: nomear. A proposição tem dois modos: ser verdadeira ou falsa. "Exatamente como uma palavra pode ser um nome, mas simplesmente um ruído carente de significado, uma expressão que aparentemente é uma proposição pode ser verdadeira ou falsa, ou pode ser carente de significado"36. Fica claro que uma proposição falsa não é uma expressão carente de significado.

\section{Considerações finais}

Apresentei as ideias que considero fundamentais para compreender a teoria da verdade do atomismo lógico de Russell. Para concluir gostaria de recapitular o núcleo dessa teoria e a insistência do autor de que a abordagem adequada é do mundo para a linguagem.

A tese fundamental do atomismo é acerca do mundo e diz que ele é constituído de muitas coisas, com propriedades e relações. Russell pensa que nós podemos apreender a estrutura do mundo uma vez que as sentenças verdadeiras espelham os fatos que expressam. É por referência a um fato

\footnotetext{
${ }^{34}$ RUSSELL, Bertrand. The Philosophy of logical atomism, p.13.

${ }^{35}$ RUSSELL, Bertrand. The Philosophy of logical atomism, p.13.

${ }^{36}$ RUSSELL, Bertrand. The Philosophy of logical atomism, p.13.
}

\begin{tabular}{|c|c|l|l|l|l|}
\hline intuitio & $\begin{array}{c}\text { ISSN } \\
1983-4012\end{array}$ & Porto Alegre & Vol.7- $\mathrm{N}^{\mathrm{o}} .1$ & $\begin{array}{c}\text { Junho } \\
2014\end{array}$ & p.182-191 \\
\hline
\end{tabular}


que uma sentença declarativa é verdadeira ou falsa. Essa correspondência é logicamente viável se a linguagem for clara.

O atomismo opõe-se ao idealismo na medida em que este não admite a multiplicidade analisável que aquele toma como ponto de partida. Trata-se, nesse caso, de uma divergência metafísica. $\mathrm{O}$ atomismo também se opõe ao pragmatismo na medida em que este concebe que uma crença é verdadeira em virtude de suas consequências. Essa é uma divergência epistemológica. Russell não aprova o consequencialismo que marca a concepção de verdade dos pragmatistas. Para ele, como vimos, uma crença é verdadeira ou falsa em virtude de um fato e jamais pelas consequências.

Descobre-se o "calcanhar de Aquiles" da teoria correspondentista da verdade ao problematizar suas suposições lógico-semânticas. A linguagem não possui a requerida clareza e precisão que Russell supõe. Demonstra-o um raciocínio de inspiração fregeana hoje conhecido como 'argumento da funda'. Mediante sucessivas substituições de expressões co-referenciais e conceitos co-extensionais, esse raciocínio mostra que todas as sentenças verdadeiras correspondem a todos os fatos. Se assim for, então a ideia de correspondência é vazia ou, como disse Davidson certa vez, ininteligível. ${ }^{37}$

\section{Referências}

AYER, Alfred. As ideias de Bertrand Russell. Tradução de Leonidas Hegenberg e Octanny Silveira da Mota. São Paulo: Cultrix; Editora da Universidade de São Paulo, 1974.

BRITO, Adriano Naves de. Nomes próprios: semântica e ontologia. Brasília: Editora UNB, 2003.

CHATEAUBRIAND, O. Logical forms: truth and description. Campinas: CLE Unicamp, 2001.

DAVIDSON, D. Truth and predication. Cambridge: Harvard University Press, 2005.

GAMUT, L. T. F. Lógica, lengua y significado: introducción a la lógica. 2.ed. Traducción de Cecilia Durán. Buenos Aires: Eudeba, 2009.

HAACK, S.. Filosofia das lógicas. Tradução de Cezar Augusto Mortari e Luiz Henrique de Araújo Dutra. São Paulo: Editora Unesp, 2002.

KIRKHAM, R. Teorias da verdade: uma introdução crítica. Tradução de Alessandro Zir. São Leopoldo: Editora Unisinos, 2003.

PEARS, David. Introduction to the 1985 edition. In: RUSSELL, Bertrand. The Philosophy of logical atomism. London: Routledge Classics, 2010.

PINTO, Paulo Roberto Margutti. "Análise argumentativa do texto On Denoting de B. Russell". Sintese Nova Fase, Belo Horizonte, v. 28, n. 90, p. 67-96, 2001.

RUSSELL, Bertrand. A análise da mente. Tradução de Antônio Cirurgião. Rio de Janeiro: Zahar Editores, 1976.

RUSSELL, Bertrand. Meu pensamento filosófico. Tradução de Brenno Silveira. São Paulo: Companhia Editora Nacional, 1960.

RUSSELL, Bertrand. Os problemas da filosofia. Tradução de Desidério Murcho. Lisboa: Edições 70, 2008.

RUSSELL, Bertrand. The Philosophy of logical atomism. London: Routledge Classics, 2010.

SANTOS, Luis Henrique dos. "Vida e obra". In: RUSSELL, Bertrand. Ensaios escolhidos. Tradução de Pablo Rubén Mariconda. São Paulo: Abril Cultural, 1978. p. v-xx. (Os Pensadores)

STRAWSON, Peter. "Sobre referir". Tradução de Balthazar Barbosa Filho. In.: RYLE et.all. Ensaios. São Paulo: Abril Cultural, 1975. p. 267-286. (Os Pensadores)

WITTGENSTEIN, Ludwig. Tractatus logico-philosophicus. Tradução e apresentação de José Arthur Giannotti. São Paulo: Companhia Editora Nacional e Editora da USP, 1968.

Recebido em: 23/08/2013

Aprovado para a publicação em: 05/05/2014

${ }^{37}$ DAVIDSON, D. Truth and predication. Cambridge: Harvard University Press, 2005, p.42.

\begin{tabular}{|c|c|c|c|c|c|}
\hline intuitio & $\begin{array}{c}\text { ISSN } \\
1983-4012\end{array}$ & Porto Alegre & Vol.7 $-\mathrm{N}^{\mathrm{o}} .1$ & $\begin{array}{c}\text { Junho } \\
2014\end{array}$ & p.182-191 \\
\hline
\end{tabular}

